\title{
FLEXIBLE URETEROSCOPIC HOLMIUM LASER INFUNDIBULOTOMY AND LITHOTRYPSY FOR THE MANAGEMENT OF CALYCEAL DIVERTICULAR STONE WITH INFUNDIBULAR ATRESIA: A CASE REPORT
}

\author{
Anil Kumar Sah ${ }^{1 *}$, Bipin Maharjan², Mahesh Bahadur Adhikari ${ }^{3}$
}

\begin{abstract}
Affiliation
1. FCPS Urology Resident, Department of Urology, Nepal Mediciti Hospital, Lalitpur, Nepal,

2. Associate Consultant Urologist, Department of Urology, Nepal Mediciti Hospital, Lalitpur, Nepal, Nepal

3. Principal Consultant Urologist and Head, Department of Urology, Nepal Mediciti Hospital, Lalitpur, Nepal, Nepal
\end{abstract}

\section{ARTICLE INFO}

Received : 15 June, 2021

Accepted : 25 January, 2022

Published : 21 February, 2022

(C) Authors retain copyright and grant the journal right of first publication with the work simultaneously licensed under Creative Commons Attribution License CC - BY 4.0 that allows others to share the work with an acknowledgment of the work's authorship and initial publication in this journal.

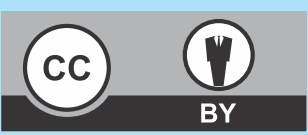

CR 43

DOI: https://doi.org/10.3126/bjhs.v6i3.43249

* Corresponding Author
Dr. Anil Kumar Sah
FCPS Urology Resident
Department of Urology
Nepal Mediciti Hospital, Lalitpur, Nepal, Nepal
Email: anil.frens@gmail.com
ORCID ID: https://orcid.org/O000-0002-9212-3985

\section{Citation}

Flexible Ureteroscopic Holmium Laser Infundibulotomy and Lithotrypsy for the Management of Calyceal Diverticular Stone with Infundibular Atresia: A Case Report. Anil Kumar Sah, Bipin Maharjan, Mahesh Bahadur Adhikari. BJHS 2021;6(3)16. 1657-1660.

\section{ABSTRACT}

Renal calyceal diverticulum is a non-secretary urothelium cavity in the renal parenchyma communicating with calyx allowing for passive filling with urine. Calyceal diverticula are found incidentally in $0.21 \%$ to $0.6 \%$ of intravenous urograms in adults. Stone formation occurs in about $10-50 \%$ cases of renal calyceal diverticula. Symptomatic case needs treatment. Digital flexible ureteroscopy with Holmium laser infundibulotomy and laser lithotripsy is beneficial in terms of shorter hospital stay, better stone clearance and minimal complications in comparison with those of other modalities. Cases of stenotic infundibulum have been addressed adequately but infundibular atresia has been rarely reported. Therefore, we present a symptomatic case of calyceal diverticular stone with infundibular atresia managed by disposable flexible ureteroscopy with holimium laser infundibulotomy and laser lithotripsy.

\section{KEY-WORDS}

Atretic Infundibulum, calyceal diverticular stone, disposable flexible ureteroscopy, holmium laser Infundibulotomy 


\section{INTRODUCTION}

It is a difficult task to manage an abnormal anatomically placed kidney stone. Minimal invasive methods like extra corporeal shock wave lithotripsy (ESWL), percutaneous nephrolithotomy (PCNL), laparoscopy and flexible ureterorenoscopy (f-URS) are the current modalities accepted for the management of renal calyceal diverticular stone (CDS). ${ }^{2}$ PCNL has better stone clearance in comparison with rest of all procedures. Fulguration of the diverticular neck with holmium laser during f-URS is found beneficial with respect to a shorter hospital stay, symptom free outcome and minimal complications. ${ }^{3}$ Though sufficient literatures are available on stenotic. Here, we report a case of renal calyceal diverticular stone managed by $\mathrm{f}$-URS with laser infundibulotomy.

\section{CASE PRESENTATION}

A 25-year-old woman presented with occasional right flank pain with minimal tenderness in right renal angle. She had no any medical and surgical history regarding urolithiasis. Urine routine examination showed microscopic hematuria. CECT scan of whole abdomen showed calyceal diverticular stone measuring $11.8 \times 9.2 \mathrm{~mm}(1218 \mathrm{HU})$ near upper pole of right kidney. There was no contrast excretion noted from the diverticulum into the calyceal system (Figure 1). She underwent disposable f-URS with laser infundibulotomy (Holmium Laser, $200 \mu \mathrm{m}, 1.0 \mathrm{~J}, 10 \mathrm{~Hz}$ at long pulse) and laser lithotripsy (Holmium Laser, 200 $\mu \mathrm{m}, 0.5-1.0 \mathrm{~J}, 0.5-10 \mathrm{~Hz}$ at both long and pulse). In the first sitting, double J (DJ) ureteral stenting was done due to failure of direct f-URS scope negotiation in tight ureter and the procedure was performed 2 weeks later in second sitting. A 9.5F f-URS was then introduced through ureteral access sheath (11/13F) for a comprehensive inspection of the renal pelvis. Fluoroscopic guided estimation of the ureteroscope and the diverticular stone was done (Figure 2). The diverticular ostium could not be located even with Blue Spritz technique. However, a small blue patch mucosa could be appreciated in one of the area near upper pole calyx (Figure 3a). Pointing the same location, laser incision was made (Figure $3 b$ ) under the fluoroscopic guidance, following which, we could visualize the infundibulum and the stone in the diverticulum (Figure 3c). Laser lithotripsy was done. We tried to place the upper end of the DJ stent into the diverticulum, but it could not be negotiated in the place.

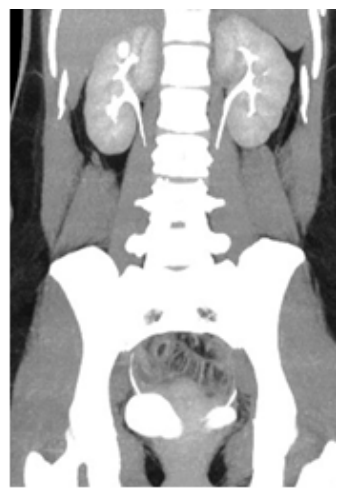

Figure 1: Preoperative CECT Image

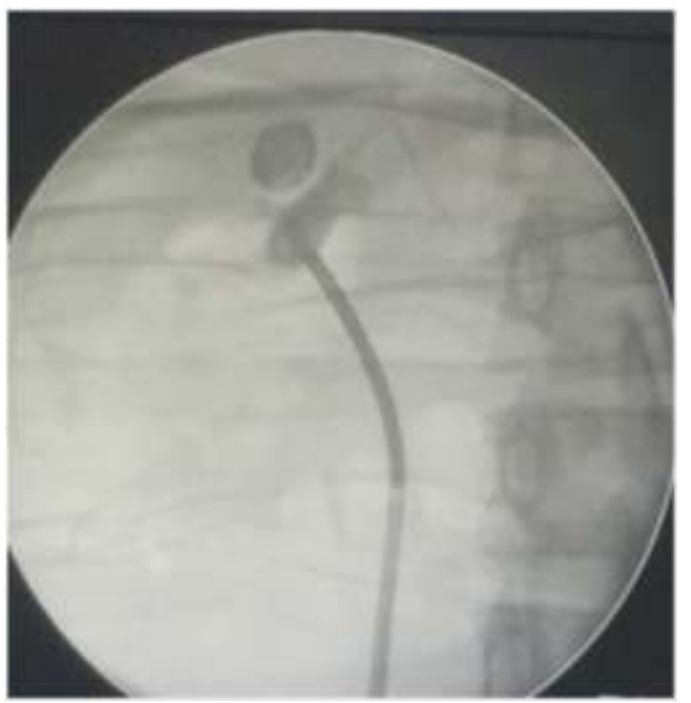

Figure 2: Fluoroscopic guided estimation of the ureteroscope and the diverticular stone
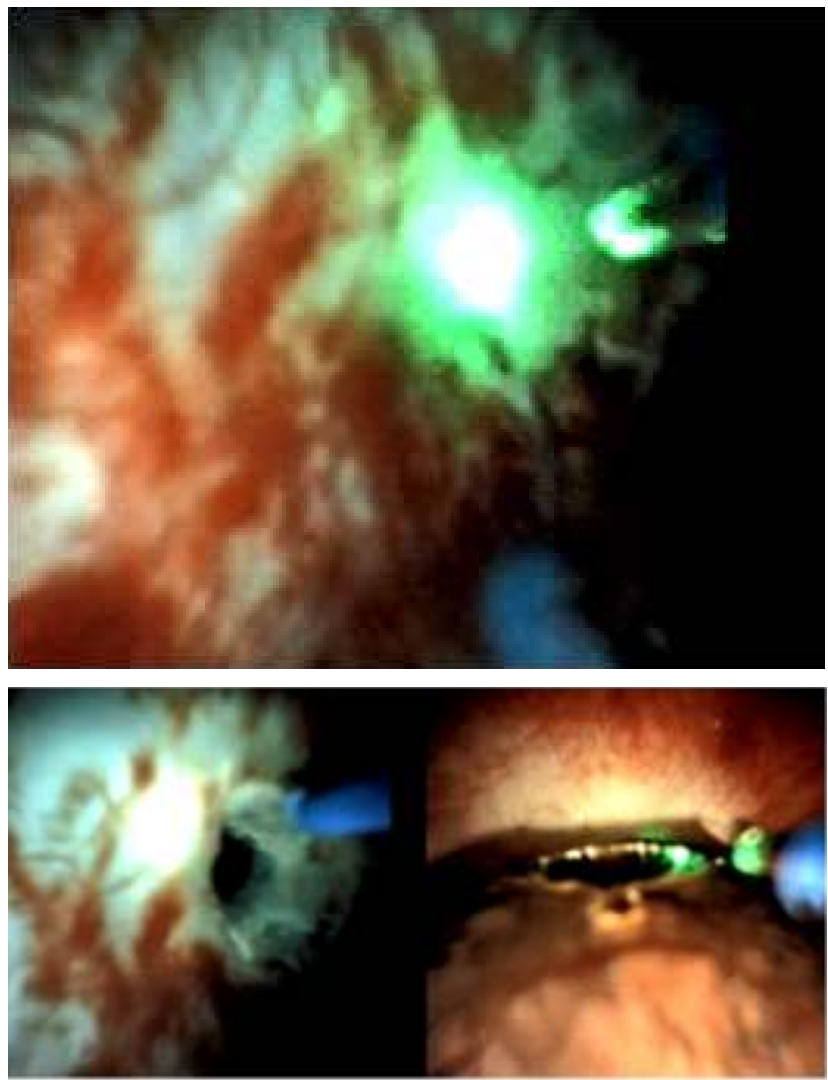

Figure 3: 3a) Blue patch mucosal area near the upper pole calyx following Blue Spritz technique, 3b) Laser infundibulotomy, 3c) Stone in diverticulum stone was identified and laser lithotripsy done.

There were no intraoperative and immediate postoperative complications. Absence of hematuria was ensured and the Foley catheter removal was done on first post-operative day. Double J ureteral stent removal was done 4 weeks postoperatively. Confirmation of complete stone clearance was done 3 months following the procedure by sonography kidney, ureter and bladder (USG KUB). 


\section{DISCUSSION}

Renal calyceal diverticulum is a non-secretary urothelium cavity in the renal parenchyma communicating with calyx allowing for passive filling with urine. Rayer first described it in 1841. Calyceal diverticula are found incidentally in $0.21 \%$ to $0.6 \%$ of intravenous urograms (IVU) on adults. ${ }^{4} \mathrm{~A}$ metaanalysis examined that $48.9 \%$ of calyceal diverticula are located in upper pole calyces, whereas in $29.7 \%$ and $21.4 \%$ of the cases, they are in the middle and lower poles respectively. A majority of studies regarding the etiopathogenesis have concluded that they are of congenital origin. However, it is multifactorial. Urinary stasis and metabolic abnormalities like hypercalciuria and supersaturation with calcium oxalate are the basic pathogenesis behind stone formation. Stone formation occurs in about $10-50 \%$ cases of renal calyceal diverticula but it may cause hematuria, pain, abscess formation and sepsis. CT Intravenous Pyelogram (CT IVP) is the standard of investigation. ${ }^{3}$

Symptomatic CDS needs treatment. ESWL, PCNL, F-URS, and laparoscopy are the principal current less invasive modalities for treating caliceal diverticular stone (CDS). ESWL is noninvasive outpatient treatment and provides pain relief in $36 \%-70 \%$ of patients. The major drawback of ESWL is that stone-free rates are low (ranging from $4 \%$ to $20 \%$ ) despite stone fragmentation (narrow infundibulum prevents clearance). Despite low stone-free rates with ESWL, most patients were rendered symptom-free with minimal complications.6 PCNL is an effective and durable means, regardless of stone size or location of the diverticulum. ${ }^{6}$ Indications of laparoscopy are limited to anterior diverticula with a thin layer of parenchyma or for anterior lesions inaccessible by endourological techniques. Longer operative time is the disadvantage.'

Many studies have concluded that operating time, rate of successful lithotripsy, symptom-free rates, success rates, stone-free rates, clinically insignificant residual fragments and minor complications were similar between PCNL and $f-$ URS for the management of CDS. The $f$-URS is beneficial in terms of shorter hospital stay and absence of major complications. ${ }^{8}$ f-URS is a good alternative in selected patients with a patent infundibulum, despite lower stone- free rates than with MPCNL. Incision of the stenosed infundibulum or diverticular lining with a high-power holmium laser and permitting the cavity to collapse are useful to increase the chance of diverticular obliteration. ${ }^{3}$ Diverticular neck identification, maintaining adequate deflection of ureterorenoscope, longer operative time and difficulty in managing lower pole CDS are the key issues of $\mathrm{f}$ URS.

Literatures on stenotic infundibulum are readily available. A study of holmium laser infundibulectomy in stenotic infundibulum by Lui K. et al (2015) concluded that CDS with stenotic infundibulum can be managed safely and efficiently with flexible ureteroscopic homium laser lithotripsy. CT IVP should be done preoperatively for the identification of stone location and prediction of difficulty during surgery. Intraoperative Blue Spritz Technique (retrograde methylene blue injection) can be used to identify the stenosed infundibulum. ${ }^{10}$ It appears to be a rapid and effective ureteroscopic strategy for fluoroscopic confirmation of filling and exact localization of the diverticulum. But the literatures on CDS with infundibular atresia are rarely available. It is safe and feasible using RIRS to perform lithotripsy in CDS. f-URS with laser infundibulotomy is a better option due to great stone free rate than ESWL, as well as lower complication rates than PCNL or laparoscopic surgery.

\section{CONCLUSION}

Management of calyceal diverticular stone with infundibular atresia by disposable flexible ureteroscopy can be performed safely with minimal complications. It is difficult to identify the location of infundibulum when Blue Spritz technique is negative. Further reports and structures study is necessary to analyse the feasibility of this procedure.

\section{PATIENT CONSENT}

The informed consent letter from the patient has been attached with the manuscript submission.

\section{CONFLICT OF INTEREST}

None

\section{REFERENCES}

1. Miller NL, Lingeman JE. Management of kidney stones. Vol. 334, British Medical Journal. BMJ Publishing Group; 2007. p. 468-72. DOI: $10.1136 / \mathrm{bmj} .39113 .480185 .80$ PMid:17332586 PMCid: PMC1808123

2. Chandran Tanabalan and Zubeir Ali. Management of calyceal diverticular stones using ultramini PCNL | Urology News [Full Text]

3. Ding X, Xu S-T, Huang Y-H, Wei X-D, Zhang J-L, Wang L-L, et al. Management of symptomatic caliceal diverticular calculi: Minimally invasive percutaneous nephrolithotomy versus flexible ureterorenoscopy. Chronic Dis TransI Med. 2016 Dec;2(4):250-6. DOI:10.1016/j.cdtm. 2016.

11.016 PMid:29063050 PMCID:PM C5643770

4. Wulfsohn MA. Pyelocaliceal diverticula. J Urol [Internet]. 1980 Jan;123(1):1-8. Available from: http://www.ncbi.nlm. nih.gov/ pubmed/6766192 https://doi.org/10.1016/S0022-5347(17)55748-1

5. Liatsikos EN, Bernardo NO, Dinlenc CZ, Kapoor R, Smith AD, Erturk E. Caliceal diverticular calculi: Is there a role for metabolic evaluation? J Urol. 2000 Jul 1;164(1):18-20.DOI: 10.1016/S00225347(05)67439-3 
6. Turna B, Raza A, Moussa S, Smith G, Tolley DA. Management of calyceal diverticular stones with extracorporeal shock wave lithotripsy and percutaneous nephrolithotomy: long-term outcome. BJU Int. 2007 Jul 1; 100(1):151-6. DOI: 10.1111/j.1464410X.2007.06911.x PMID: 17552962

7. Miller SD, Ng CS, Streem SB, Gill IS. Laparoscopic management of caliceal diverticular calculi. J Urol [Internet]. 2002 Mar [cited 2020 Apr 14];167(3):1248-52. DOI: 10.1016/S0022-5347(05)65275-5

8. Bas O, Ozyuvali E, Aydogmus Y, Sener NC, Dede O, Ozgun S, et al. Management of calyceal diverticular calculi: a comparison of percutaneous nephrolithotomy and flexible ureterorenoscopy. Urolithiasis. 2015 Mar 19;43(2):155-61. DOI: 10.1007/s00240-0140725-5 PMID:25249328
9. Auge BK, Munver R, Kourambas J, Newman GE, Preminger GM. Endoscopic management of symptomatic caliceal diverticula: A retrospective comparison of percutaneous nephrolithotripsy and ureteroscopy. In: Journal of Endourology Mary Ann Liebert Inc.; 2002 p. 557-63. DOI: 10.1089/089277902320913233, PMID:12470462

10. Liu K, Xiao C, Liu Y, Hao Y, Zhang S, Tian Y, et al. [Management of calyceal diverticular calculi with stenotic infundibulum by flexible ureteroscopic holmium laser infundibulectomy and lithotripsy]. Beijing Da Xue Xue Bao 2015 Aug 18; 47(4):618-21. DOI: 10.1016/ s0377-1237(11)60044-0 PMID: 27365809 PMCID: PMC4920886

11. Ng WM. Retrograde intrarenal surgery in atretic calyceal diverticular stone, a case report. Urol Case Reports [Internet]. 2019;24 (December 2018):100840. DOI: 10.1016/j.eucr. 2019.100840 PMID:31211051 PMCID:PMC6562262 